\title{
Calf and replacement heifer mortality from birth until weaning in pasture-based dairy herds in New Zealand
}

\author{
E. L. Cuttance, ${ }^{* 1}$ W. A. Mason, ${ }^{*}$ J. McDermott, ${ }^{\star}$ R. A. Laven, $†$ S. McDougall, $\ddagger$ and C. V. C. Phyn§ \\ *VetEnt, 49 Benson Road, Te Awamutu, New Zealand, 3800 \\ †Institute of Veterinary, Animals and Biomedical Sciences, Massey University, Palmerston North, New Zealand, 4474 \\ $\ddagger$ Cognosco, Anexa Farmers Vet Club, 25 Moorhouse St., Morrinsville, New Zealand, 3300 \\ §DairyNZ Ltd., Private Bag 3221, Hamilton 3240, New Zealand
}

\section{ABSTRACT}

The aims of this study were to (1) estimate the perinatal (birth to $24 \mathrm{~h})$ and postnatal $(\sim 24 \mathrm{~h}$ to the mean weaning age of $13 \mathrm{wk})$ mortality risk in pasture-based dairy calves until weaning, and (2) identify associated risk factors in the 2015 calving season. A prospective survey of 32 seasonal calving dairy farms was undertaken. Farmers recorded (daily) the number and sex of the calves alive or dead in the paddocks where cows calved. All daily animal movements in and out of the calf rearing facilities, including death and euthanasia, and the identification of the animals (if applicable) were recorded, and a survey of the farm management practices was undertaken. Individual and farm-level risk factors for perinatal mortality were modeled separately using generalized logistic mixed models with a random effect fitted for herd. Postnatal mortality incidence risk was calculated using time at risk for each calf from $24 \mathrm{~h}$ of age, collapsed into weeks, and multiplying the incidence risk by the mean weaning age of the study population. Farm-level risk factors contributing to postnatal mortality in the first week of life were assessed using a multivariable logistic mixed regression model. The mean perinatal mortality risk was $5.7 \%$ (95\% confidence interval 5.4 to $6.1 \%$ ) with a range from 2.2 to $8.6 \%$ (18,437 calves, 30 farms). Perinatal calf mortality was greater for male relative to female calves (odds ratio 1.39; $95 \%$ confidence interval 1.22 to 1.59 ), calves born in the first week of the calving period in comparison to wk 2 to 11 (odds ratio 0.32 to 0.66 ), and those born on days with greater rainfall (odds ratio 1.01 per $1 \mathrm{~mm}$ increase; $95 \%$ confidence interval 1.00 to 1.02). At the farm level, perinatal mortality increased for every extra week of calving period length (odds ratio 1.12; 95\% confidence interval 1.06 to 1.17 ). The mean postnatal

Received February 24, 2017.

Accepted July 1, 2017.

${ }^{1}$ Corresponding author: emma.cuttance@vetent.co.nz mortality risk was $4.1 \%$ (95\% confidence interval 3.6 to $4.6 \%$ ) with a range of 0 to $11 \%$ between farms. Farmlevel risk factors contributing to mortality in the first week of life included farmer-reported disease problems in calves (odds ratio 2.2; 95\% confidence interval 1.62 to 2.96 ), or calves hand-fed colostrum in the first $12 \mathrm{~h}$ of life (odds ratio 1.66; $95 \%$ confidence interval 1.26 to 2.19 ), which was assumed to be associated with poor colostrum quality and bacterial contamination. Regional differences were also observed in both perinatal and postnatal mortality risks, indicating that weather conditions, herd size, and management variations contribute to mortality incidence. In summary, the mortality risk of perinatal calves and postnatal calves until weaning on pasture-based farms is comparable with data published from other dairying systems despite the notable management differences. Several risk factors were identified that could be managed to reduce mortality incidence of dairy calves.

Key words: mortality, perinatal, postnatal, calf, dairy

\section{INTRODUCTION}

Calf mortality is a significant economic and welfare concern on dairy farms worldwide (Mee, 2008a). Unsurprisingly, interest is growing in characterizing the incidence and risk factors associated with calf mortality to develop reduction strategies.

The timing of calf mortality can be categorized into 2 phases: (1) perinatal mortality, which typically refers to mortality of full-term calves during parturition and up to 24 (or $48 \mathrm{~h}$ ) after birth, and (2) postnatal mortality, which refers to mortality after the perinatal period, up to a designated time point, such as weaning. Although case definitions and data accuracy can vary, estimates of perinatal mortality incidence risk range from 3 to $9 \%$ across dairy industries internationally, and the postnatal mortality incidence risk until weaning is reported at between 5 and 11\% (Compton et al., 2017). However, most published studies on calf mortality have been conducted in housed systems where cows calve indoors 
and animal management, disease risk, per cow milk production, genetics, and nutrition are quite different from pasture-based dairy systems, such as those operated in New Zealand and Australia, or in Ireland and other parts of Europe. Few retrospective studies have estimated the incidence of perinatal mortality in these herds where cows often calve outdoors (4 to 7\%; Pryce et al., 2006; Berry et al., 2007; Mee et al., 2008) and in those studies the quality of the data is variable. For example, Mee et al. (2008) reported that, in the database they used to examine calf mortality in pasture-based herds in Ireland, $46 \%$ of herds had no recorded perinatal mortality data. A similar situation may occur in the New Zealand system, as calves that are stillborn, that are born alive but die within $48 \mathrm{~h}$, and the majority of male dairy calves are not permanently identified with an ear tag number and are, therefore, commonly not entered into the software recording systems. Furthermore, to our knowledge, no reports have been published of postnatal mortality incidence rates in pasture-based systems, even though mortalities of these animals may be of greater welfare concern and incur a greater financial cost, relative to calves that are stillborn or aborted. A more accurate estimation of perinatal and postnatal mortality incidence risk is, therefore, required to benchmark these systems.

A wide variety of risk factors have been associated with perinatal and postnatal mortality including dystocia (Wells et al., 1996; Gundelach et al., 2009; Bleul, 2011), age of dam, twin calving, year, sex of calf (Mee et al., 2008; Bleul, 2011), and first colostrum feeding method, timing, and volume (Wells et al., 1996; Tyler et al., 1998). These risk factors were almost exclusively identified in systems where cows calved indoors, and limited data are available in pasture-based systems where cows calve outdoors during late winter/early spring with minimum supervision. In seasonally concentrated pasture-based calving systems, newborn calves are born outside and are left there with their dams for 1 to $24 \mathrm{~h}$ before being collected and brought into the indoor calf rearing facility. The variation in collection time is dependent on whether farmers collect newborn calves once or twice a day in New Zealand. The calf rearing facilities typically have a shed design that is open on one side as has multiple sections or pens within them. Calves are managed in groups of 10 to 20 per pen until approximately 1 mo of age, following which calves are commonly given access to pasture during the day until approximately 3 mo of age. They are weaned based on either quantity of grain or concentrate consumption, weight, or age and then grazed outside for the remainder of their lives. At approximately 6 mo of age, the majority of calves are transported to a separate farm (grazier) where they are grown, mated, and then returned home at approximately 22 mo before calving (Cuttance et al., 2017). To develop strategies to reduce calf mortality on pasture-based dairy farms, it is imperative that calf- and farm-level risk factors that are important under these conditions are identified.

The aims of this prospective study were, therefore, to determine the perinatal $(\sim 0-24 \mathrm{~h}$ old $)$ and postnatal (i.e., from entry to the calf rearing shed until the time of weaning) mortality risk of dairy calves in a pasturebased system, and to identify potential risk factors for mortality.

\section{MATERIALS AND METHODS}

\section{Experimental Design}

This study was a prospective, observational study of 32 seasonal, pasture-based dairy farms from the Waikato, North Island (n = 19; region 1$)$ and Canterbury, South Island $(\mathrm{n}=13$; region 2 ) regions of New Zealand. This study and the associated survey were approved by the New Zealand Ethics Committee (Dunedin), application number 2015\#32.

The farms were primarily chosen from a cohort of 35 farms already randomly selected to be part of another study investigating the incidence, risk factors, and long-term effects of failure of passive transfer (FPT) in dairy calves. Herd selection for the original study was performed by listing all the dairy clients of the veterinary practice VetEnt in the Waikato, and then, separately, the dairy clients of VetEnt in Canterbury, in alphabetical order. The clients were divided by the total number of farms to be included in the FPT study (18 per region) then every nth farm was selected (i.e., systematic random sampling). Due to difficulty in securing enrollment in region 2, an extra farm was enrolled in region 1 and was selected randomly from the remaining clients in the same manner as the original selection. The farmers that agreed to participate and were enrolled in the FPT study were then invited to participate in this calf and heifer replacement mortality study. If farmers declined to participate in this study or failed to meet the inclusion criteria, another farmer was chosen by systematic random sampling of the remaining VetEnt clients that were not already involved in the FPT study in that region.

The herd inclusion criteria were that all cows in the herd were due to calve between July and October (spring calving) and the farmer was willing to record, on a daily basis, the number and sex of calves found alive or dead in the paddocks where the cows calved. They also had to agree to the recording of all animal 
movements in and out of the rearing sheds daily, including the identification of dead animals (if they had ear tag identification). The farmer had to be willing to record, or allow technicians to record, all identification of calves on the day of weaning. In addition, their contractor who was going to rear the female animals identified as replacements through to entry to the milking herd had to be willing to record all mortality and any stock movements during this time at grazing. If the farm selected from the systematic random sample did not meet these criteria, the next farmer on the list was chosen and assessed for the same criteria.

The farmer could choose to record these data either directly onto a record form provided, into a farm diary or notebook, electronically (MindaPRO, LIC, Hamilton, New Zealand), or another method. The method of data recording was discussed and defined for each farm during a meeting before the study commenced. Herds were visited weekly by technicians, and data were photocopied where written records were used, or extracted from electronic records. While calves were in the rearing facility (i.e., d 1 up until weaning), data were recorded daily, including the number of male and female calves that died, were euthanized, were sent away for slaughter, were sold, or were weaned. Any animal ear tag identification (completed within $2-3 \mathrm{~d}$ of arriving into the rearing facility) was recorded alongside their movements (if applicable). Animals that died without a tag were labeled either as "bobby," if they were intended for slaughter (meat processing market) at 4 to $7 \mathrm{~d}$ old or as "no tag," to indicate that these animals were heifers or bulls, and that the farmer intended on rearing as either replacements or for sale as older animals, but that at the time of death had not yet been given an identification tag. The data recording began from time of entry to the calf shed and continued through until weaning.

Farmers also were required to supply any associated verifying documentation that accompanied a calf movement, including, for example, bobby calf collection dockets from transport operators, bobby calf processing receipts from the meat works, sold animal receipts or bank payments for sale animals and dead stock animal receipts (dead calves collected from the farm), and access to their electronic records.

Records collected from the farmer was cross checked against all available documentation. The total number of calves born were checked against both the farm's electronic and paper records of cows calved. Bobby calf numbers sent were confirmed by both the bobby calf collection dockets and the processing receipts. Sold calf numbers were confirmed with receipts of sale or invoices where possible. Dead animals were confirmed by following-up receipts of dead animals collected off the farm for discrepancies where applicable. Only the movements to other farms (friends, family, or different farms under the same owner) that were not accompanied by official documentation were unable to be cross checked (approximately 5\%).

Finally, the identity of all weaned animals was confirmed by the technicians who were present at that time. Using these data, a daily tally was monitored and any discrepancies (animals not accounted for) were followed up as soon as possible with the farmer to detect where the errors were occurring. At the end of the study, an attempt was made to define the fate of every calf born as weaned, died, euthanized, or sent to slaughter.

A survey of farm management practices (Supplemental Tables S1-S5; https://doi.org/10.3168/jds .2017-12793) was completed with the farmer and calf rearer at the completion of calving. Data pertaining to numbers of cows, and calving pattern of the herd were extracted from MindaPRO at the end of the calving period. Questions pertaining to individual management were answered by the farmer and were not otherwise validated.

Daily weather records of rain $(\mathrm{mm})$ and minimum and maximum temperature $\left({ }^{\circ} \mathrm{C}\right)$ were collected from the NIWA (www.niwa.co.nz) website for the nearest weather station to each farm $(5-30 \mathrm{~km}$ radius from the farm) for use in the risk factor analysis.

\section{Statistical Analysis}

Perinatal Mortality. A total of 187 animals, 86 of which were dead, were removed from the data set due to being born more than $3 \mathrm{SD}$ ( $15 \mathrm{~d}$ ) before the planned start of calving (PSC) for the herd. The PSC was defined as the start of the mating period from the previous year calculated forward by $282 \mathrm{~d}$. Gestation length for each calf was not collected nor analyzed, as it is common practice in New Zealand for records of nonreplacement calves not to be linked to their dam. Two farms from region 2 humanely euthanized 771 calves (farm $\mathrm{a}=416$ and farm $\mathrm{b}=355$ ) by free bullet or captive bolt instead of sending them to the slaughter plant, as standard practice. As it was not possible to determine whether some of these euthanized calves would have died of illness, these farms were removed from the perinatal component of the mortality analyses.

The incidence risk of perinatal mortality for each farm and the population mortality incidence risk for all calves were calculated and presented on a dot plot. The numerator was all calves born dead, or that died before they were brought into the calf rearing shed (a period of between 0 to $24 \mathrm{~h}$ from birth); the denominator was all calves born on farm. 
Locally weighted nonlinear regression analysis was conducted for the daily mortality risk relative to the PSC (Dohoo et al., 2010); this was presented using locally weighted regression curves to assess trends in the data. The weekly risk of mortality was also compared with the total numbers of animals born on each week relative to their herd PSC.

Multivariable Analyses. Individual calf mortality was modeled using a generalized logistic mixed model, with a random effect fitted for herd, following the criteria recommended by Zuur et al. (2009) and Dohoo et al. (2010) to account for the clustering of data within herds. The multivariable model began with a full model, with all possible calf level risk factors included. Potential risk factors included calf sex, region, week born relative to PSC, daily minimum and maximum temperature, and daily rainfall.

Linearity of associations between the continuous weather variables and mortality were assessed by plotting them against the $\log$ odds of mortality. If they were visually assessed to be nonlinear, they were either categorized or centered around their mean, and appropriate polynomial functions were added to the model. Biologically plausible 2-way interaction terms included in this model were between days from PSC and sex, and interactions between weather variables and region.

Fixed variables were dropped from the model using backward elimination, if the log-likelihood ratio test between nested models had a significance of $P>0.05$, until all remaining fixed effects were significant at $P \leq$ 0.05 . A variable was considered a confounder if coefficients or standard errors of the remaining fixed effects were altered by $\geq 20 \%$, and these were retained in the model even if not significant.

Farm-level risk factors obtained from the survey (Supplemental Table S1; https://doi.org/10.3168/ jds.2017-12793) were investigated independently in a separate model to the calf-level risk factors; this was done due to missing variables in the farm level survey that would have excluded several calves in the individual calf analysis Unconditional relationships between farm-level risk factors and perinatal mortality were assessed using generalized mixed models; variables were retained for multivariable analysis if $P<0.2$. The clustering of individuals within farm was accounted for by including farm as a random effect. This ensured that the appropriate degrees of freedom were used for farm level risk factors, and pseudo-replication did not occur. Due to the large number of variables, only biologically plausible interactions were investigated. Explanatory variables for the multivariable mixed logistic regression model were identified using backward stepwise selection process with variables removed from the model if the log-likelihood ratio test between nested models had a significance of $P>0.05$, until all remaining fixed effects were significant at $P \leq 0.05$. A sensitivity analysis was conducted to assess if the inclusion of animals that had calved greater than $15 \mathrm{~d}$ before the PSC had a significant effect $(P \leq 0.05)$ on the inferences; a mortality risk was also calculated with these extra animals to see if the mortality risk changed.

Postnatal Calf Mortality. Postnatal mortality included all deaths and euthanized animals from $24 \mathrm{~h}$ old to weaning. Replacement calves from the 2 farms that humanely euthanized nonreplacement calves were included in the postnatal mortality analysis. However, 2 farms were removed due to recording and compliance issues, leaving 30 farms available for postnatal analysis.

To calculate mortality risk and survival of the calves once they had reached the rearing shed, time at risk (i.e., period in the calf rearing facilities) was calculated for each calf. To ensure that the mortality risk of all animals was calculated rather than just the mortality of tagged animals, several assumptions were made for animals with a missing date of birth:

(1) Animals confirmed as sent to slaughter for the bobby calf market that were removed from the farm but did not have a recorded date of birth were assumed to have been born less than $7 \mathrm{~d}$ before leaving the farm $(\mathrm{n}=9,073)$.

(2) Sold animals that did not have a recorded date of birth were considered to have been born within 1 standard deviation of the mean time at risk for sold animals that had a date of birth recorded; these animals were randomly allocated a date of birth within that 1 standard deviation $(\mathrm{n}=$ $1,283)$.

(3) All animals that were weaned but did not have a recorded date of birth were allocated a date of birth corresponding to the average weaning age from the farm $(\mathrm{n}=1,036)$.

(4) All dead or euthanized animals that were labeled as "bobby" were assumed to be less than $1 \mathrm{wk}$ old to be in line with the first assumption $(\mathrm{n}=$ $68)$.

(5) All dead or euthanized animals that were recorded as "no tag" were assumed to be less than $1 \mathrm{wk}$ old as they had not yet received their designated ear tag identification in the time frame agreed by the farmer $(\mathrm{n}=86)$.

Time at risk for all animals was collapsed into weeks, and this reduced most of the potential error of these assumptions. Weekly mortality risk was calculated by dividing the number of dead animals by the sum of 
time at risk (in weeks). Weaning varied between farms with a mean farm weaning age of $13.0 \mathrm{wk}$ and a range of 9.2 to 15.9 wk. To account for this variation, a risk of mortality from $24 \mathrm{~h}$ of age to weaning (postnatal mortality) for each farm was calculated by multiplying the weekly mortality risk by the mean weaning age (13 wk) of the study population.

The risk of postnatal mortality on each farm, along with the population mortality risk estimate with $95 \%$ confidence intervals, were calculated and presented on a dot plot. To assess hazard of mortality of the calves, weekly instantaneous hazard curves, with $95 \%$ confidence intervals were produced for the postnatal period.

Multivariable Analysis of Mortality Risk in the First Week of Life. Mortality in the first week of life was analyzed using a multivariable logistic mixed regression model. Animals that died or were euthanized in the first week of life after reaching the rearing shed were included in the numerator and all animals that were alive at $\mathrm{d} 1$ were included in the denominator for this analysis.

Unconditional relationships between farm-level risk factors and postnatal mortality in the first week of life on a farm were assessed using generalized mixed models with a logit link, and were retained for multivariable analysis if $P<0.2$. Due to the large number of variables, only biologically plausible interactions were investigated. Explanatory variables for the multivariable mixed logistic regression model were identified using backward stepwise selection process with variables removed for the model if the log-likelihood ratio test between nested models had a significance of $P>0.05$, until all remaining fixed effects were significant at $P \leq$ 0.05 .

Attempts to use Cox's proportional hazards model were abandoned due to violations of the assumptions required for such a model. All data analyses were conducted using $\mathrm{R}$ v3.1.2 (R Development Core Team, 2014; R Foundation for Statistical Computing, Vienna, Austria).

\section{RESULTS}

\section{Perinatal Mortality}

There were a total of 1,053 deaths from 18,437 calves (9,845 males and 8,592 females) from 30 farms (17 in region 1 and 13 in region 2), which equated to a mortality risk of $5.7 \%$ (95\% CI 5.4 to $6.1 \%$ ) across all calves. The farm-level range of perinatal mortality risk was 2.2 to $8.6 \%$ (Figure 1). The mortality risk for male calves was $6.5 \%$ (95\% CI 6.0 to $7.0 \%$ ), with a range across farms from 1.5 to $10.0 \%$ (Figure 2a). The mortality risk for female calves was $4.8 \%$ (95\% CI 4.3 to $5.3 \%$ ), with a range across farms from 1.1 to $10.3 \%$ (Figure $2 b$ ). When the animals that had were born greater than 15 $\mathrm{d}$ before the PSC were added to the analysis, there were a total of 1,139 deaths from 18,624 calves, a mortality risk of $6.1 \%$ (95\% CI 5.8 to $6.5 \%$ ).

The weekly risk of mortality relative to the PSC for both male and female calves is presented in Figure 3. The risk of mortality did not vary between the sexes by week relative to the PSC $(P=0.75)$. However, a significant effect of week was observed from the PSC on mortality $(P<0.001)$, as calves born before the PSC had greater odds of perinatal mortality, with the risk declining thereafter until wk 11 (Figure 3 and Table 1); the increase seen in Figure 3 toward the end of the calving season was not significant and was likely an artifact of small numbers. This relationship indicated that the perinatal mortality risk was not related to the number of animals born.

\section{Individual Calf Risk Factors for Perinatal Mortality}

The generalized logistic mixed model for individual calf risk factors contributing to the perinatal mortality of calves is presented in Table 1. Calf mortality

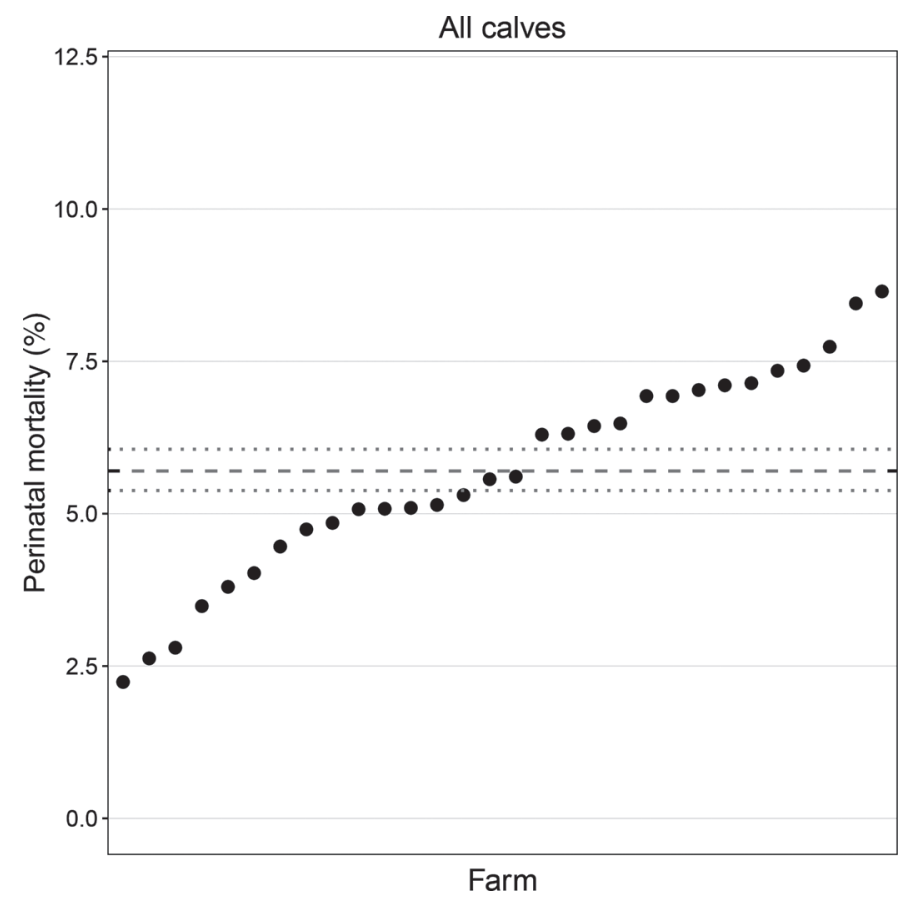

Figure 1. Dot plot of the incidence of mortality of all calves in the paddock ( $\mathrm{n}=30$ farms, 18,437 calves). The horizontal dashed line represents the raw population mortality percentage (5.7\%), and the dotted lines above and below indicate the $95 \%$ CI of the population percentage. 
a) Male calves

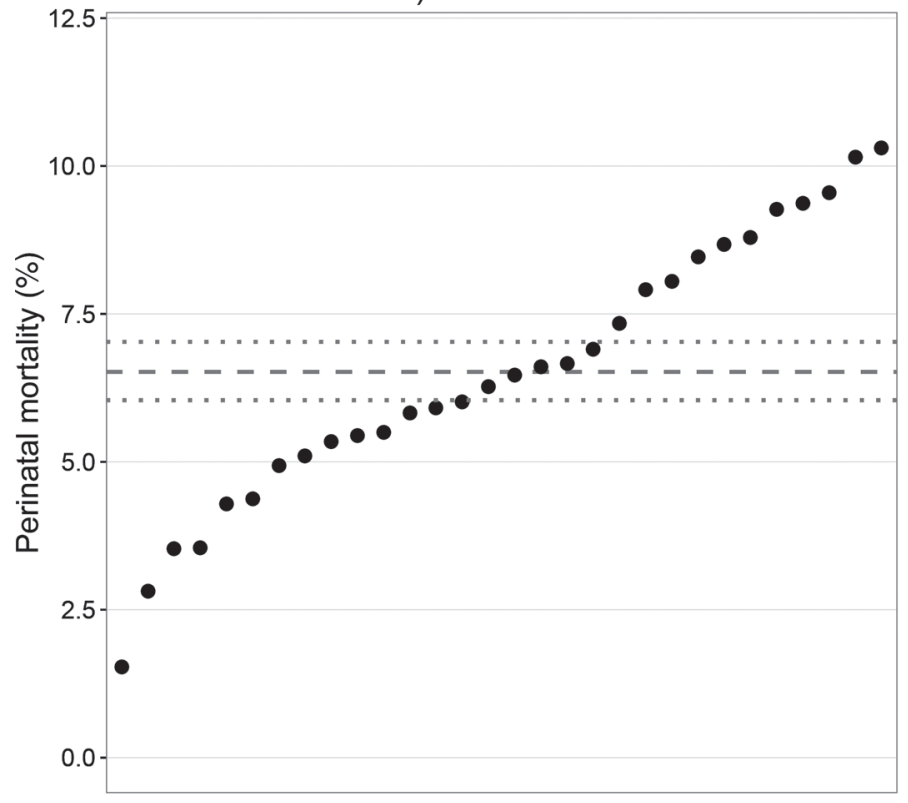

Farm b) Female calves

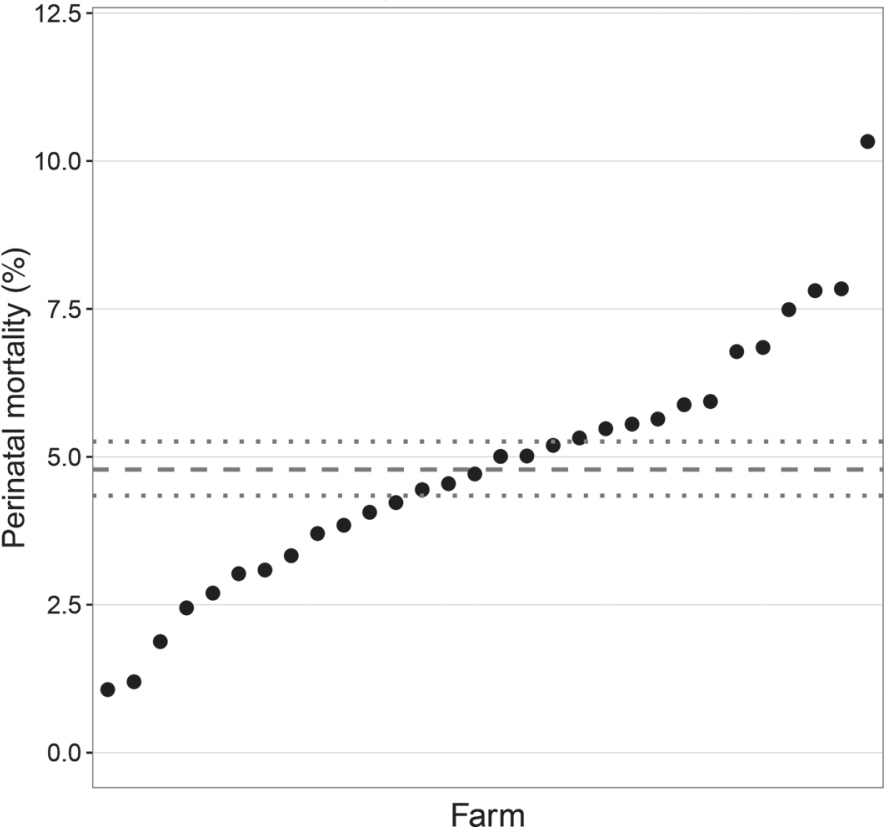

Figure 2. Dot plot of the incidence of perinatal mortality of female $(\mathrm{n}=8,592)$ and male calves $(\mathrm{n}=9,845)$. The horizontal dashed line represents the raw population mortality percentage for females $(4.8 \%)$ and males $(6.5 \%)$, and the dotted lines above and below indicate the $95 \%$ CI of the population percentage.

was greater for male calves, for calves born in region 2 (South Island), for calves born in the first week of the calving period (relative to wk 2 to 11 of the calving period), and for calves born on days with increased rainfall. For every $10 \mathrm{~mm}$ of extra rainfall on the day of birth, odds of death increased by $8 \%$. The only analyzed factor that did not significantly contribute to the mortality of dairy calves in the paddock was daily minimum or maximum temperature $\left({ }^{\circ} \mathrm{C}\right)$. Sensitivity analysis indicated that if all dead calves were included, regardless of if they were born $3 \mathrm{SD}$ before PSC (86/187 calved animals), the risk factors and their significance did not change.

\section{Farm-Level Risk Factors for Perinatal Mortality}

All potential farm-level (29 farms) risk factors analyzed are presented in Supplemental Tables S1 to S5 (https://doi.org/10.3168/jds.2017-12793). Farmer perception of calf mortality performance is presented in Supplemental Table S6 (https://doi.org/10.3168/jds .2017-12793). For every extra week of calving period length, the odds of perinatal mortality increased by $12.0 \%$ (95\% CI 6.0 to $17.0 \%$ ). The odds of perinatal death was $0.2(95 \%$ CI 0.06 to $0.03 \% ; P<0.01)$ when the primary calf rearer was aged 41 yr or older, compared with calf rearers aged between 20 and $30 \mathrm{yr}$ old, and farms that had male calf rearers were also associated with a lower odds of perinatal mortality (odds ratio $0.25 ; 95 \%$ CI 0.11 to $0.37 \% ; P<0.01$ ), compared with farms with female calf rearers.

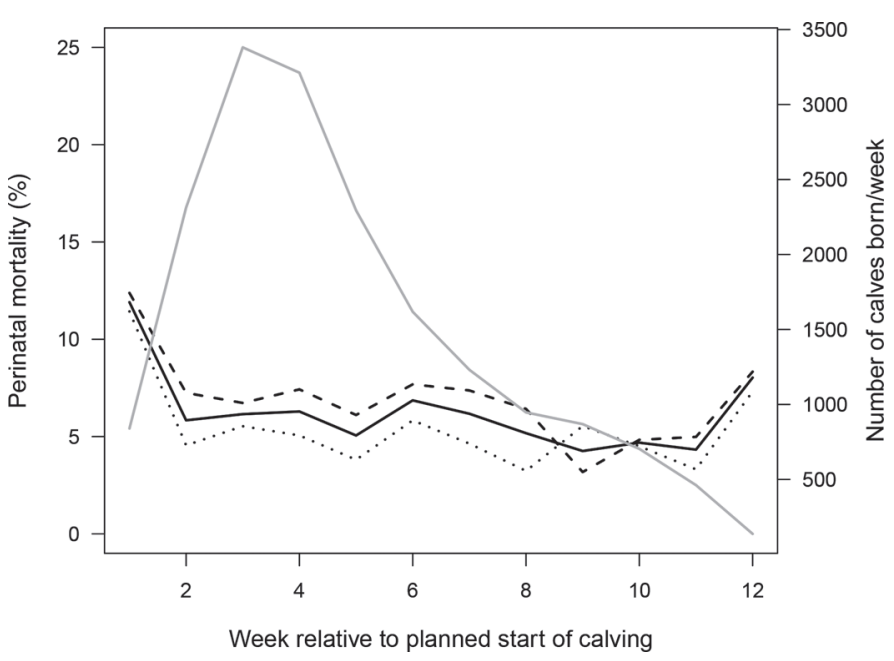

Figure 3. Line plot of the perinatal mortality percentage relative to the planned start of calving. The solid line represents all calves. The dashed line represents the male calves, and the dotted line represents the female calves. The gray line shows the total number of calves born over the same time period. The $\mathrm{x}$-axis range is from $15 \mathrm{~d}$ before the planned start of calving to $70 \mathrm{~d}$ postcalving. 


\section{Postnatal Calf Mortality}

A total of 17,169 animals entered the rearing sheds. One hundred thirty-six (0.8\%) had been born, but had no record as to their fate (i.e., sold, bobbied, reared). These animals were excluded from the analysis, leaving 17,033 animals for analysis.

Of these calves entering the rearing sheds, 100 calves died and 177 were euthanized. The risk of mortality of calves in the shed for each farm from $24 \mathrm{~h}$ of age to the mean weaning age of $13 \mathrm{wk}$ is presented in Figure 4. The mortality risk was $4.1 \%$ (95\% CI 3.6 to $4.6 \%$ ), with a range of postnatal mortality between farms from 0.0 to $11.0 \%$.

The weekly instantaneous hazard rate of mortality from 1 to $7 \mathrm{~d}$ of age was $1.1 \%$ (95\% CI 1.0 to $1.2 \%$ ), and then decreased to less than $0.4 \%$ per week for the remaining weeks until weaning (Figure 5).

\section{Individual and Farm-Level Risk Factors for Postnatal Mortality During the First Week of Life}

The intention was to use a multivariable Cox proportional hazard model, with farm as a frailty term to analyze the individual and farm level risk factors for the survival data. However, the model consistently collapsed and had multiple violations of assumptions and, as a result, was not reported.
Twenty-nine farms had a complete survey of risk factors and were analyzed in a multivariable logistic regression. Calves that were born on farms in region 1 had a 0.58 (95\% CI 0.44 to $0.68 \%)$ odds of death in the first week of life, compared with calves born on farms in region 2. Farms that had farmer-reported disease in calves, such as diarrhea, pneumonia, or navel ill, during the postnatal period had 2.20 times (95\% CI 1.62 to $2.96 \%$ ) greater odds of calves dying, compared with farmers that did not report any disease problems. Finally, farmers who reported that they gave calves their first hand-fed colostrum within the first $12 \mathrm{~h}$ of life had an increased odds of calf mortality in the first week of life (odds ratio 1.66; $95 \%$ CI 1.26 to $2.19 \%$ ), compared with farmers that reported that calves received their first hand-fed colostrum between 12 to $24 \mathrm{~h}$ after birth.

\section{DISCUSSION}

This study is the first known prospective evaluation of calf mortality and associated risk factors, during the perinatal and postnatal periods, on pasture-based farms. The prospective data collection method allowed for greater precision than previous retrospective analysis of records, as there was less reliance on farmer recording and validation checks were performed throughout the entirety of the study. Hence, the results reported are likely to be an accurate representation of perinatal

Table 1. Generalized logistic mixed model with farm as a random effect for significant individual risk factors contributing to the mortality of dairy calves from birth to approximately $24 \mathrm{~h}$ old (before calf was bought to the calf-rearing shed)

\begin{tabular}{|c|c|c|c|c|c|c|c|}
\hline Risk factor & $\begin{array}{c}\text { No. of dead } \\
\text { calves }\end{array}$ & $\begin{array}{l}\text { Total no. } \\
\text { of calves }\end{array}$ & Estimate & $\mathrm{SE}$ & $\begin{array}{l}\text { Odds } \\
\text { ratio }\end{array}$ & $\begin{array}{c}\text { Lower and } \\
\text { upper } 95 \% \text { CI }\end{array}$ & $P$-value \\
\hline Intercept & - & - & -2.75 & 0.164 & - & - & - \\
\hline Female & 408 & 8,547 & Referent & - & - & - & - \\
\hline Male & 638 & 9,787 & 0.263 & 0.068 & $1.39^{1}$ & $1.22-1.59$ & 0.025 \\
\hline Region 1 & 384 & 7,775 & Referent & - & - & - & - \\
\hline Region 2 & 662 & 10,559 & 0.286 & 0.117 & 1.30 & $1.03-1.63$ & 0.008 \\
\hline Week $1^{2}$ & 64 & 654 & Referent & - & - & - & - \\
\hline Week 2 & 124 & 2,047 & -0.431 & 0.166 & 0.65 & $0.47-0.90$ & 0.01 \\
\hline Week 3 & 200 & 3,331 & -0.412 & 0.155 & 0.66 & $0.49-0.90$ & 0.008 \\
\hline Week 4 & 196 & 3,307 & -0.453 & 0.156 & 0.64 & $0.47-0.86$ & 0.004 \\
\hline Week 5 & 112 & 2,455 & -0.718 & 0.170 & 0.49 & $0.35-0.68$ & $<0.001$ \\
\hline Week 6 & 100 & 1,628 & -0.417 & 0.174 & 0.66 & $0.47-0.93$ & 0.02 \\
\hline Week 7 & 82 & 1,320 & -0.439 & 0.185 & 0.64 & $0.45-0.93$ & 0.02 \\
\hline Week 8 & 49 & 972 & -0.675 & 0.214 & 0.50 & $0.33-0.77$ & 0.002 \\
\hline Week 9 & 39 & 899 & -0.831 & 0.229 & 0.44 & $0.28-0.68$ & $<0.001$ \\
\hline Week 10 & 28 & 701 & -0.898 & 0.261 & 0.41 & $0.24-0.68$ & $<0.001$ \\
\hline Week 11 & 15 & 499 & -1.132 & 0.324 & 0.32 & $0.17-0.61$ & $<0.001$ \\
\hline Week 12 & 17 & 282 & -0.350 & 0.301 & 0.70 & $0.39-1.27$ & 0.245 \\
\hline Week 13 & 20 & 239 & 0.050 & 0.298 & 1.05 & $0.59-1.89$ & 0.867 \\
\hline Rainfall (mm) & $\mathrm{NA}^{3}$ & NA & $0.008^{4}$ & 0.004 & 1.01 & $1.00-1.02$ & 0.024 \\
\hline
\end{tabular}

${ }^{1}$ Male calves had 1.39 (95\% CI 1.25-1.61) times the risk of being dead in the paddock in comparison to females.

${ }^{2}$ Week 1 may be before the planned start of calving as it is based on 3 consecutive calving events that may be 3 SD away from the planned start of calving for that farm.

${ }^{3} \mathrm{NA}=$ not applicable.

${ }^{4}$ For every $10 \mathrm{~mm}$ of extra rainfall, the odds of mortality increased by $8 \%$ (95\% CI 1-16\%). 


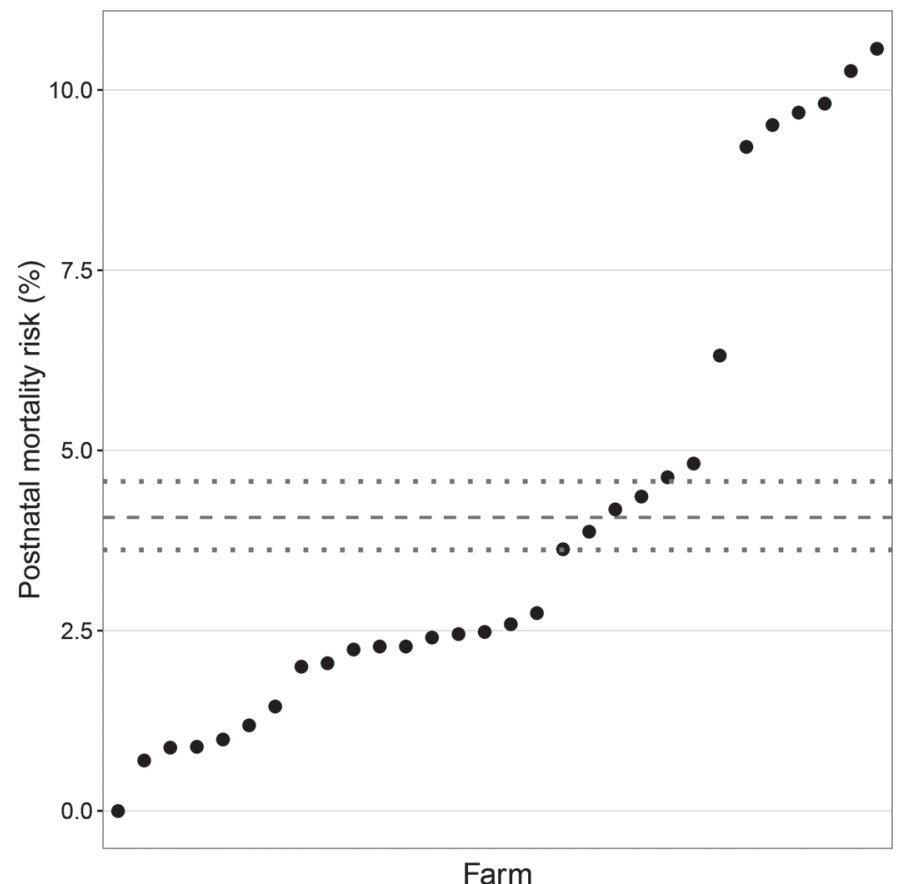

Farm

Figure 4. Dot plot of the incidence of postnatal mortality of all calves from $1 \mathrm{~d}$ of age to mean weaning age (13 wk of age; $\mathrm{n}=30$ farms, 17,033 calves). The horizontal dashed line represents the mean incidence $(4.1 \%)$, and the dotted lines above and below indicates the $95 \%$ CI of the mean.

and postnatal calf mortality in pasture-based herds, at least in the season evaluated.

\section{Perinatal Mortality Risk}

The perinatal mortality incidence determined in this study was similar to the mean perinatal mortality of $6 \%$ reported for previous international studies (Compton et al., 2017). Furthermore, the incidence of perinatal mortality in the present prospective study was consistent with earlier retrospective studies in pasture-based systems where calves are born outdoors (Pryce et al., 2006; Berry et al., 2007). Together, these findings indicate that perinatal mortality incidence is comparable between various pasture-based and housed systems.

Due to the random selection of the farms included in the study and single year it was completed, it is possible that the results are representative farms within their region on a particular year (or nearby regions) but not necessarily applicable to the far north or south regions of New Zealand due to some differences in management, pasture, and weather in these regions. In addition, due to the intensive nature of recording that was required to be included in the study and the fact the presence of only 32 farms in the study, it is pos-

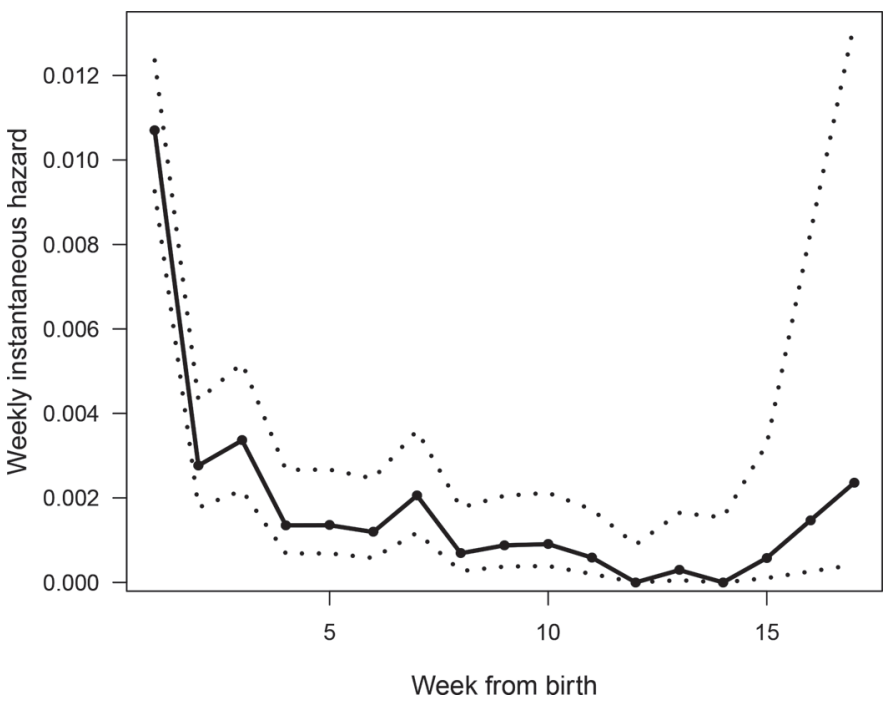

Figure 5. Line plot of the mean instantaneous hazard of postnatal mortality for calves in the rearing shed across all farms $(n=30)$. The solid line represents the mean instantaneous hazard, and dashed lines above and below represent the $95 \%$ CI of the mean.

sible that this may have biased the farm selection to those who already have good recording systems, good management, and acceptable mortality. It is possible that farmers with a mortality incidence at the higher end may have been unwilling to participate. However, no farmers in the study knew what their mortality percentage was and most thought that their farm calf mortality was average or better than average relative to other farms in New Zealand (despite not knowing what their mortality percentage was). On the 2 farms that humanely euthanized a large number of calves, nothing indicated that their management of animals during the perinatal period was any different from any other farm (other than the euthanasia policy); therefore, removing these 2 farms was unlikely to have altered the perinatal mortality.

Due to study design, a cut-off had to be determined for when to include animals relative to the PSC. It was decided that the animals that calved greater than 15 $\mathrm{d}$ before the PSC for the herd would remove a portion of animals that were aborting. So it was expected that this excluded group of 187 calves would have a higher mortality risk (46\%). When these animals were added back into the analysis, the total perinatal mortality risk increased from 5.7 to $6.1 \%$; however, the confidence intervals for these overlapped, and the difference between these 2 figures are unlikely to be clinically important. Sensitivity analysis revealed that the exclusion of these animals had no effect on the risk factors for perinatal mortality. Apart from these excluded animals, no other 
effort was made to exclude or differentiate stillborn animals from animals born alive but dying within the first $24 \mathrm{~h}$ of life. Routine pharmacologically induced parturition is prohibited in New Zealand, so no calves were included in this category.

Several calf-level factors were identified that increased the odds of an individual calf dying during the perinatal period. For example, we found that male calves were more likely to die than female calves, probably because male calves have higher levels of dystocia due to their greater fetal size (Laster et al., 1973; Johanson and Berger, 2003; Mee, 2008a). However, this relationship may be due to a reduced level of care and attention given to male calves compared with female calves, due to their lower economic value.

In a seasonal system, the timing of a calf's birth relative to the bulk of the herd's calving dates is also an important factor associated with the risk of perinatal mortality. The current study identified that calves born before the PSC had a greater risk of mortality, with mortality decreasing (in a nonlinear fashion) with increasing weeks following the PSC. Although the data set was corrected to remove obvious abortions, it is possible that the higher proportion of mortality in the beginning of the calving season was, at least in part, due to late-term abortions. However, this relationship is more likely to be due to less farmer observation and organization at the beginning of the seasonal calving period and the calving of nulliparous, which tend to be bred to calve earlier in seasonal calving pasture-based systems and have a greater risk of dystocia relative to multiparous cows (Uematsu et al., 2013; Mee et al., 2014). Further work investigating the cause of increased mortality risk in animals early in the calving season may help direct how to best help farmers reduce perinatal mortality.

It is uncertain why calves born in region 2 (Canterbury, South Island) had a higher odds of perinatal mortality relative to region 1 (Waikato, North Island). Further work is needed to determine if the relationship is due to a combination of climatic variables, dry cow feed management or transition diet (which differ between regions), less established dairying community, education differences, farmer attitude differences, or other unmeasured management factors.

Finally, higher daily rainfall contributed to higher perinatal mortality risk. This size of this appears small when considering the change per $1 \mathrm{~mm}$ of rain, but if a large rainfall occurs all at once, the practical effect is potentially very large. Given that calves were born outdoors in late winter/early spring, it was surprising that minimum and maximum temperature were not significant risk factors, nor were they confounders.
However, the wind velocity was unable to be extracted consistently off the NIWA website for most farms; this factor may have had an interaction with temperature that was not able to be analyzed in the current study.

Although multiple farm-level risk factors were identified as contributing to perinatal mortality, they do not necessarily imply causality and may be proxies for other factors. For example, the age or sex of the calf rearer logically should not have an influence on the mortality before the calves reach the rearing facility. However, the association of older ( $\geq 41 \mathrm{yr}$ ) calf rearers with reduced perinatal mortality may be due to the experience of this individual informing the farm protocols for the management of freshening cows around calving, management of dystocia, and the collection and caring of calves before they reach the rearing facility. It may also be associated with farm ownership or management structure; for example, three-quarters of the older calf rearers in this study were part of an owner-operator structure, which, in turn, may be associated with better calving management due to ownership and attention to detail. This relationship is similar for male calf rearers. Often if the primary calf rearer is male, it is not their sole job on farm. They are either the farm owner or manager of a small farm where they rear all the calves as well as being responsible for management of calving cows and feeding; hence, they may influence perinatal mortality in ways other than the job of the calf rearer. All the male calf rearers in this study were from an owner-operator-structured farm. However, although entered as a separate variable, owner-operator did not show a significant relationship in the multivariable model.

\section{Postnatal Mortality Risk}

Despite substantial differences relative to their evaluated farm management systems, such as calves born all-year-round and all animals being reared to weaning, our estimates of $4.1 \%$ postnatal mortality in a pasturebased system are similar to the 3.1 and $6.5 \%$ incidence risks reported by Azizzadeh et al. (2012) and Svensson et al. (2006). These latter studies provide the closest comparison to this current study, as they measured calf mortality risk from $24 \mathrm{~h}$ to $90 \mathrm{~d}$. The reduction in postnatal mortality in the current study demonstrates that the first week of life for a calf is the period of greatest risk, with the risk of mortality decreasing considerably over time.

Unsurprisingly, farmers that reported disease problems during the whole postnatal calf rearing period were more likely to have calves dying in the first week of life after reaching the calf rearing facility. Calves 
are most at risk during a young age from disease while their immune system is still developing (McGuirk, 2008, Mee, 2008b).

The observation in the current study that removal of calves from the dam followed by hand-feeding colostrum within $12 \mathrm{~h}$ of birth was associated with increased risk of postnatal mortality is not consistent with international data. However, in the companion study assessing calf FPT (Cuttance et al., 2017), farmers that left the calves with the dam for $24 \mathrm{~h}$ had a lower risk of calf FPT. This relationship was probably because of low antibody concentrations and high bacterial counts in stored colostrum associated with the feeding of pooled and poorly preserved colostrum fed to calves less than $24 \mathrm{~h}$ of age (Denholm et al., 2017). Therefore, if farmers were removing calves from dams early (less than $12 \mathrm{~h}$ ) and hand-feeding them colostrum, we postulate that they were more likely to have a higher prevalence of FPT and, therefore, more likely to have increased mortality (Tyler et al., 1999; Svensson et al., 2006). Improved colostrum feeding and quality management practices may be a key approach to improving postnatal calf mortality rates.

Postnatal mortality in the first week of life also differed between regions. Similar to the association with perinatal mortality risk, calves born in region 2 (Waikato, North Island) had a lower risk of postnatal mortality relative to region 1 (Canterbury, South Island). The influence of weather conditions, herd size, and management variations are possible contributors to the reason(s) for the differences in mortality risk seen between the 2 regions. However, other contributing factors will require a larger study to investigate.

The range of postnatal mortality risk between farms was larger than the range of perinatal mortality incidence in the paddock. Furthermore, whereas no farmers achieved $0 \%$ perinatal mortality, 1 farm did achieve $0 \%$ calf mortality during the postnatal period. The implications of these findings are that influencing postnatal calf mortality may be more achievable than managing perinatal calf mortality. If the 6 farms with the highest postnatal mortality risk were removed from the analysis, postnatal mortality risk decreased by $33 \%$ to $2.7 \%$. If the industry could identify those farms that have higher than expected postnatal mortality risk, and put control methods in place, then the nationwide postnatal mortality risk could be reduced substantially. This premise is supported by the survey information, which indicates many opportunities for farmers to improve their colostrum and calf rearing management. Unfortunately, the size of this study was not able to detect the level or magnitude of the influence that specific management factors might have on mortality throughout the whole rearing period.

\section{CONCLUSIONS}

The mortality risk of perinatal calves and postnatal calves until weaning on pasture-based farms is comparable with data published from systems where cows are calved indoors. Substantial variation in mortality risk between farms was evident; hence, reductions in calf mortality may be achievable on many farms. Further research using a larger number of farms is required to investigate risk factors, both at the individual calf and farm levels, which will provide a better understanding of practical changes that could reduce the incidence of calf mortality on farm.

\section{ACKNOWLEDGMENTS}

This study was funded by the New Zealand Ministry of Business, Innovation and Employment (Wellington, NZ; contract number DRCX1302) and by New Zealand dairy farmers through DairyNZ Inc. (Hamilton, NZ; contract number RD1405). The authors gratefully acknowledge the participation and technical support of the enrolled farmers and Veterinary Enterprises Group Ltd. The also thank C. Compton (Massey University) and S.-A. Turner (DairyNZ Ltd.) for their critical review of the study design and advise on data collection and interpretation.

\section{REFERENCES}

Azizzadeh, M., H. F. Shooroki, A. S. Kamalabadi, and M. A. Stevenson. 2012. Factors affecting calf mortality in Iranian Holstein dairy herds. Prev. Vet. Med. 104:335-340.

Berry, D., J. Lee, K. Macdonald, and J. Roche. 2007. Body condition score and body weight effects on dystocia and stillbirths and consequent effects on postcalving performance. J. Dairy Sci. 90:4201-4211.

Bleul, U. 2011. Risk factors and rates of perinatal and postnatal mortality in cattle in Switzerland. Livest. Sci. 135:257-264.

Compton, C., C. Heuer, P. Thomsen, T. Carpenter, C. Phyn, and S. McDougall. 2017. Invited review: A systematic literature review and meta-analysis of mortality and culling in dairy cattle. J. Dairy Sci. 100:1-16.

Cuttance, E., W. Mason, R. Laven, and C. Phyn. 2017. Prevalence and individual risk factors of failure of passive transfer in New Zealand dairy calves. N. Z. Vet. J. In press.

Denholm, K., J. Hunnam, E. Cuttance, and S. McDougall. 2017. Colostrum quality on New Zealand dairy farms. N. Z. Vet. J. In press.

Dohoo, I., W. Martin, and H. Stryhn. 2010. Veterinary Epidemiologic Research. 2nd ed. University of Prince Edward Island, Charlottetown, Prince Edward Island, Canada.

Gundelach, Y., K. Essmeyer, M. K. Teltscher, and M. Hoedemaker. 2009. Risk factors for perinatal mortality in dairy cattle: Cow and foetal factors, calving process. Theriogenology 71:901-909.

Johanson, J., and P. Berger. 2003. Birth weight as a predictor of calving ease and perinatal mortality in Holstein cattle. J. Dairy Sci. $86: 3745-3755$.

Laster, D. B., H. A. Glimp, L. V. Cundiff, and K. E. Gregory. 1973. Factors affecting dystocia and the effects of dystocia on subsequent reproduction in beef cattle. J. Anim. Sci. 36:695-705.

McGuirk, S. M. 2008. Disease management of dairy calves and heifers. Vet. Clin. North Am. Food Anim. Pract. 24:139-153. 
Mee, J. F. 2008a. Prevalence and risk factors for dystocia in dairy cattle: A review. Vet. J. 176:93-101.

Mee, J. F. 2008b. Newborn dairy calf management. Vet. Clin. North Am. Food Anim. Pract. 24:1-17.

Mee, J. F., D. P. Berry, and A. R. Cromie. 2008. Prevalence of, and risk factors associated with, perinatal calf mortality in pasturebased Holstein-Friesian cows. Animal 2:613-620.

Mee, J. F., C. Sanchez-Miguel, and M. Doherty. 2014. Influence of modifiable risk factors on the incidence of stillbirth/perinatal mortality in dairy cattle. Vet. J. 199:19-23.

Pryce, J. E., B. L. Harris, and A. W. McPherson. 2006. Genetics of stillbirth in dairy calves. Vol. 66. Pages 98-102 in Proc. New Zealand Society of Animal Production. New Zealand Society of Animal Production, Napier.

Svensson, C., A. Linder, and S. O. Olsson. 2006. Mortality in Swedish dairy calves and replacement heifers. J. Dairy Sci. 89:4769-4777.

Tyler, J. W., D. D. Hancock, J. G. Thorne, C. C. Gay, and J. M. Gay. 1999. Partitioning the mortality risk associated with inadequate passive transfer of colostral immunoglobulin's in dairy calves. J. Vet. Intern. Med. 13:335-337.

Tyler, J. W., D. D. Hancock, S. E. Wiksie, S. L. Holler, J. M. Gay, and C. C. Gay. 1998. Use of serum protein concentration to predict mortality in mixed-source dairy replacement heifers. J. Vet. Intern. Med. 12:79-83.

Uematsu, M., Y. Sasaki, G. Kitahara, H. Sameshima, and T. Osawa. 2013. Risk factors for stillbirth and dystocia in Japanese Black cattle. Vet. J. 198:212-216.

Wells, S. J., D. A. Dargatz, and S. L. Ott. 1996. Factors associated with mortality to 21 days of life in dairy heifers in the United States. Prev. Vet. Med. 29:9-19.

Zuur, A., E. N. Ieno, N. Walker, A. A. Saveliev, and G. M. Smith. 2009. Mixed Effects Models and Extensions in Ecology with R. Springer-Verlag, New York, NY. 